\title{
What is "marked" in visual marking? Evidence for effects of configuration in preview search
}

\author{
MELINA A. KUNAR \\ University of Wales, Bangor, Wales \\ GLYN W. HUMPHREYS \\ University of Birmingham, Birmingham, England \\ KELLY J. SMITH \\ Medical Sciences Teaching Centre, Oxford, England \\ and \\ JOHAN HULLEMAN \\ University of Birmingham, Birmingham, England
}

\begin{abstract}
Visual search for a conjunction target is facilitated when distractor sets are segmented over time: the preview benefit. Watson and Humphreys (1997) suggested that this benefit involved inhibition of old items (visual marking, VM). We investigated whether the preview benefit is sensitive to the configuration of the old distractors. Old distractors changed their location prior to the occurrence of the new items, while also either changing or maintaining their configuration. Configuration changes disrupted search. The results are consistent with object-based VM, which is sensitive to the configuration of old stimuli.
\end{abstract}

Our survival in a rapidly changing world containing multiple objects is contingent on having efficient means of selecting stimuli for action. This article is concerned with an exploration of the properties of one proposed mechanism of selection: visual marking (VM).

\section{Visual Marking}

Watson and Humphreys (1997) introduced the term VM to describe a procedure in which old items can be deprioritized for selection by top-down inhibition. Evidence for VM came from an adaptation of a standard form-color conjunction search task (detect a blue $\mathrm{H}$ among blue $\mathrm{A}$ and green $\mathrm{H}$ distractors). In a novel preview search condition, the green $\mathrm{H}$ distractors were presented prior to the blue letters (the distractors plus the target, when present). Watson and Humphreys (1997) found that search in the preview was efficient relative to a standard conjunction baseline. To account for this, they proposed that the locations of the old items were inhibited (or visually marked), and thus, they did not interfere with search.

Direct evidence for a causal role of inhibitory processes in the preview effect has come from studies in which a

This work was supported by a BBSRC studentship to M.A.K. and by an MRC grant to G.W.H. Correspondence concerning this article should be addressed to M. A. Kunar, School of Psychology, University of Wales, Brigantia Building, Bangor LL572DG, Wales (e-mail: mkunare @ bangor.ac.uk) probe-dot procedure has been used. Olivers and Humphreys (2002) and Watson and Humphreys (2000) both found that it is difficult to detect a probe dot appearing at the location of an old item, relative to a probe appearing at the location of a new stimulus. Interestingly, this occurs only when the probe task is embedded within a visual search procedure, in which participants carry out a search task on the majority of trials. When the only task is probe detection, there is no benefit from probes that fall on new items, rather than old ones (Olivers \& Humphreys, 2002; Watson \& Humphreys, 2000). Hence, the result is not due simply to masking or to automatic attentional capture by new stimuli. The result is dependent on an intentional set established in the search task. Olivers and Humphreys (2002) also demonstrated that probe detection for old items selectively improved when participants undertook a secondary task when the old items were first presented. This was consistent with a decrease in inhibition under dual-task conditions, since the amount of attentional resources needed for VM were reduced.

In contradiction to the above arguments for intentiondependent inhibition of old items (VM), two alternative accounts of preview search have been proposed. First, Donk and Theeuwes (2001) maintained that the preview benefit reflects automatic attentional prioritization of new stimuli defined by onsets. These investigators found no preview benefit when the new stimuli were isoluminant with the background, so that new items were not defined 
by onsets. Thus, Donk and Theeuwes concluded that new items must show a luminance onset in order to produce efficient preview search. A second alternative proposal states that the preview benefit comes about through grouping and segmentation of the old and the new items into distinct temporal displays (Jiang, Chun, \& Marks, 2002). Here, attention could be individually applied to each display in turn, so long as the displays could be temporally segregated.

In the present study, we explored the factors that determine the preview benefit in search by manipulating the relations between the old and the new items. In particular, we asked what would happen if old items changed their locations prior to the onset of the new stimuli and also changed their configuration? The configural manipulation is relevant to the distinction between the VM and the other accounts of preview search. For example, since the onset capture account stresses only the properties of the new stimuli, performance should be indifferent to whether the old items change or maintain their configuration. Similarly, performance should be indifferent to configural change if temporal grouping alone is crucial, provided the temporal relations between the old and the new items are constant. Hence, evidence for an effect of configural change would argue against these accounts, although it would be consistent with an explanation in terms of VM.

\section{Effects of Change and the Representation of the Old Items}

Our study was concerned with the effects of stimulus change on the preview benefit in search. There have now been several investigations of how stimulus change can influence the preview effect. For example, Jiang et al. (2002) found that the preview effect was disrupted if a change occurred at the locations of the old items when the new items onset. However, no disruption was found if, instead, (1) changes were made to the background of the search display or (2) changes were made at the locations the old items prior to the onset of the new.

Watson and Humphreys (1997) also found that some dynamic changes, occurring at the locations of the old stimuli (i.e., if they offset their contours or "blinked" off and on), were disruptive to the preview effect. However, the same manipulations are not necessarily disruptive if they are consistent with ecological changes that would occur when the stimuli remained present in the real world. Kunar, Humphreys, Smith, and Watson (2003), for example, introduced transient changes to old items by having them disappear behind occluders before reappearing along with the new stimuli. They found that performance was then equivalent to performance when there were no transient changes to previews (and there was a preview effect relative to a conjunction baseline). This result suggests that the preview benefit is contingenton maintaining a representation of old stimuli across occlusion conditions. Inhibition of this representation may generate the preview effect. We note also that this result is not consistent with an onset capture account. Transient changes to old items may disrupt onset capture (as in Watson \&
Humphreys, 1997), but this should occur irrespective of whether occlusion relations are present.

Kunar, Humphreys, and Smith (2003) have presented additional evidence that the preview benefit can survive transient change. Here, a novel top-up preview procedure was developed. In this top-up procedure, old items appeared and then were offset. They then reappeared for a brief period prior to the occurrence of the new stimuli. The time between the second appearance of the old items and the onset of the new items was too short to generate a substantial preview benefit in its own right (i.e., without any earlier presentation of the old items; see Kunar, Humphreys, \& Smith, 2003; see also Watson \& Humphreys, 1997, for data on the time course of the preview benefit). Despite this, Kunar, Humphreys, and Smith (2003) found that a preview benef it could be generated if an earlier presentation of the old items was shown. This earlier appearance seemed to "topup" the representation of the old items established just before the presentation of the new stimuli, to produce a preview benefit. This result suggests that the "history" of the old items does matter and, again, is difficult to explain within an onset capture framework. In the cases in which transient change is disruptive to preview search, the old items have typically reappeared with the new (e.g., Watson \& Humphreys, 1997). The simultaneous onset of the two sets of stimuli could provide a grouping cue that then makes it difficult to selectively reject the old items from search (Jiang et al., 2002). Nevertheless, when this grouping cue is abolished by re-presenting the old items just before the new (in the top-up procedure), participants use a representation of the old items to facilitate search. In this article, we again investigate the influence of the representations of the old items on search by manipulating their previous configural grouping and location arrangement.

\section{What Is Marked in Static and Moving Stimuli?}

Watson and Humphreys (1997) proposed that the preview benefit was based on VM and that this involved inhibition of the location of the old items. The evidence on poor detection of probe dots at old locations is consistent with this (Olivers \& Humphreys, 2002; Watson \& Humphreys, 2000). According to Watson and Humphreys (1997), even though the old and the new stimuli they presented differed in color as well as location, the color difference was not crucial (although see Gibson \& Jiang, 2001, for some opposing evidence). Certainly, color is not necessary for the preview benefit to occur, since similar benefits have been reported with displays in which old and new stimuli had the same color (Olivers, Watson, \& Humphreys, 1999; Theeuwes, Kramer, \& Atchley, 1998; see also the present Experiments 1-3).

The picture seems somewhat different for moving stimuli though. Olivers et al. (1999) and Watson and Humphreys (1998) found that a preview benefit was obtained when both old and new items moved across the display, but only when the old and the new sets differed in color (see also Kunar, Humphreys, \& Smith, in press). These authors have proposed that old moving items can be rejected from search by inhibition of their common color (e.g., through 
a color map; cf. Treisman \& Sato, 1990). Thus, there may be different mechanisms involved in marking static and moving stimuli (i.e., location- and color-based inhibition, respectively). In further research, the effect of spatial grouping has been investigated with moving preview displays that contained no color difference between old and new items. Watson (2001) found that even when there were no color differences present, moving items could still generate a preview benefit if their interspatial relationships remained constant. Here, it appears that the old items can be rejected efficiently if they group into a particular spatial configuration. Perhaps, then, it is also possible that similar grouping effects could influence performance with static stimuli.

One possible grouping cue that could influence search with static items is color. Even if color differences are not necessary to generate the preview benefit with static stimuli (see Olivers et al., 1999; Theeuwes et al., 1998), they could still contribute. Indeed, Olivers and Humphreys (2003) have shown effects of color carry-over in preview search with static items. They investigated the effects of singleton capture, using search displays in which either a target or a distractor was the "odd one out" in terms of color. Normally, response times (RTs) to targets are facilitated when targets are singletons and are slowed when distractors are singletons (Theeuwes, 1992). Olivers and Humphreys (2003) showed that these singleton effects were greatly diminished if previews were presented in which the old items shared the color of the singleton. They attributed this to a negative carry-over of color from the preview to the search display. Possibly, grouping (and inhibition) of old distractors by common color can contribute to the efficient selection of new items in preview search. If carried across from old to new distractors, any color-based inhibition would then affect the processing of new items in the same color.

In the present study, we investigated whether another property of static displays, the configuration of the items, can contribute to the preview benefit. We used a new procedure to assess the effects of configural change on search. In the critical conditions, participants first saw a set of old items randomly located in the field (for $450 \mathrm{msec}$ ). These stimuli then offset and moved to new positions, where they remained static for a further $300 \mathrm{msec}$ before the appearance of the new stimuli. With a 300-msec preview alone, we would not expect to observe an optimum preview benefit (Watson \& Humphreys, 1997; also replicated here). We tested whether the earlier presentation of the old items influenced search by comparing performance with a standard preview condition, in which the old items remained in place for the full preview period $(750 \mathrm{msec}$, in Experiments 1 and 2). In the two critical conditions, the old items undergoing the location change either altered their configuration or maintained their configuration. We assessed whether maintenance of the configuration facilitated performance, relative to when there were both configural and position changes. Prior studies of visual search have demonstrated sensitivity to configural relations be- tween the items in a single display (in carry-over effects across trials; Jiang \& Chun, 2001). Here, we tested whether the same would hold for preview search conditions.

We report four experiments. In Experiments 1 and 2, we used within-form conjunctions to investigate the effects of changing (1) the location, but not the configuration, of the old stimuli (Experiment 1) and (2) both the locations and the configuration of the old items (Experiment 2). Each effect was measured relative to a standard preview baseline. In Experiment 3, we compared effects of location and configuration change directly, in a within-subjects design. We also compared both these conditions with a 300-msec preview condition, to see whether the prior presentation of the old items would have any effect over and above that of seeing the preview for $300 \mathrm{msec}$ prior to the search display. In Experiment 4, we evaluated performance when old and new items differed in color. We assessed whether configural information could contribute to preview search even under this condition.

\section{EXPERIMENT 1 \\ Effects of Changing the Location, but Not the Old Configuration, in Shape-Defined Preview Search}

\section{Method}

\section{Participants}

Fifteen participants ( 3 males and 12 females) participated for course credit. Their ages ranged from 19 to 29 years (mean age, 20.6 years), and they were all taken from a population of undergraduates at the University of Birmingham. All the participants had normal or corrected-to-normal eyesight.

\section{Stimuli}

The stimuli were taken from Olivers et al. (1999) and consisted of capital Ts presented in different orientations. The distractor items were either upright Ts or Ts rotated counterclockwise $90^{\circ}$ from the vertical. The target item was always an upside down T. The letters, subtending a visual angle of $0.8^{\circ} \times 0.8^{\circ}$ at an observation distance of $60 \mathrm{~cm}$, were randomly positioned in 10 possible locations within a stimulus field with a visual angle of $11.8^{\circ} \times 11.8^{\circ}$.

There were three search conditions: a conjunction baseline, a location-different-configuration-same (LD-CS) preview, and a standard preview condition. The conjunction and preview conditions comprised 4,8 , or 16 items in total, and the target was present on half the trials. In the preview conditions, one set of distractors (containing $n / 2$ upright Ts, if the total display size equals $n$ ) were presented ahead of the second set (90. rotated Ts and an inverted T, when present). In the experiment proper, each search condition was presented in a separate block (for conjunction, standard preview, and LD-CS preview displays). The experimental blocks each contained 120 trials $(20$ per display size $\times$ present/absent). The order of the blocks was counterbalanced across participants.

\section{Design and Procedure}

In the conjunction search, a fixation dot was presented for $1,000 \mathrm{msec}$ before the target item (if present), which appeared simultaneously alongside upright $\mathrm{T}$ and rotated $\mathrm{T}$ distractors (rotated $90^{\circ}$ counterclockwise). The participants were asked to search for the inverted T. In the LD-CS preview, the fixation dot appeared in the center of the screen for 1,000 msec, after which upright Ts appeared at random locations in the field. ${ }^{1}$ After $450 \mathrm{msec}$, these Ts were displaced (after an interstimulus interval [ISI] of $0 \mathrm{msec}$ ) vertically one visual degree and then remained there for $300 \mathrm{msec}$ before rotated 
Ts and (possibly) the target (an inverted T) appeared. In the standard preview condition, the fixation dot again appeared in the center of the screen for 1,000 msec before upright Ts were added alongside. These stayed at the same location for $750 \mathrm{msec}$ before the second set of items were added (rotated T's and the target, when present). In all the conditions, the participants were urged to keep their eyes on the fixation dot until the second set of stimuli appeared. This end display remained visible until the participant made a response; however, a time-out period of $10 \mathrm{sec}$ was installed, so that if a response was not elicited during this period, the next trial ensued. Figure 1 presents examples of the displays.

\section{Results}

Figure 2 shows the mean correct RTs as a function of the display size and target presence or absence, for each condition. The error rates are given in Table 1, and Table 2 shows the descriptive statistics.

\section{RTs}

Standard preview versus LD-CS preview. Present trials were faster than absent ones $[F(1,14)=27.14, p<$ $.01]$, and RTs increased with increases in display size $[F(2,28)=77.74, p<.01]$. However, there was no effect of condition $[F(1,14)=0.02$, n.s.]. There were no interactions involving the condition factor (all $F_{\mathrm{S}}<1.0$ ). The only reliable interaction was between target and display size $[F(2,28)=14.39, p<.01]$. The effects of the display size were larger on absent than on present responses.

Conjunction versus LD-CS. All three main effects were significant: RTs were shorter in the LD-CS preview than in the conjunction condition $[F(1,14)=81.25, p<$ $.01]$; present trials were faster than absent ones $[F(1,14)=$ $62.37, p<.01]$; and RTs increased with increases in display size $[F(2,28)=169.83, p<.01]$. There were also significant interactions of condition and target $[F(1,14)=$ $45.24, p<.01]$, condition and display size $[F(2,28)=$ $43.44, p<.01]$, target and display size $[F(2,28)=37.43$, $p<.01]$, and condition, target, and display size $[F(2,28)=$ $20.00, p<.01]$. Examining the condition $\times$ display size interaction further, we see significant effects of condition at display size $4[t(29)=7.1, p<.01]$, display size 8 $[t(29)=7.3, p<.01]$, and display size $16[t(29)=6.6$, $p<.01]$.

When present trials only are considered, the main effects both of condition $[F(1,14)=34.47, p<.01]$ and of display size $[F(2,28)=73.63, p<.01]$ were significant. RTs in the LD-CS preview condition were shorter than those in the conjunction condition, and RTs also increased with increases in display size. The interaction between condition and display size was also significant $[F(2,28)=6.24, p<$ $.01]$. Breaking the analysis down further, we see a significant effect at display size $4[t(14)=4.7, p<.01]$, display size 8 $[t(14)=5.2, p<.01]$, and display size $16[t(14)=5.9$, $p<.01]$. The effects of display size were smaller in the LD-CS preview than in the conjunction condition.

Conjunction versus standard preview. All three main effects were significant: RTs were shorter in the preview than in the conjunction condition $[F(1,14)=58.60, p<$ $.01]$; present trials were faster than absent trials $[F(1,14)=$

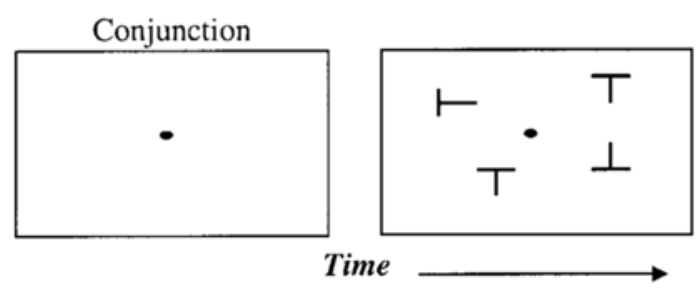

Location-different-configuration-same preview
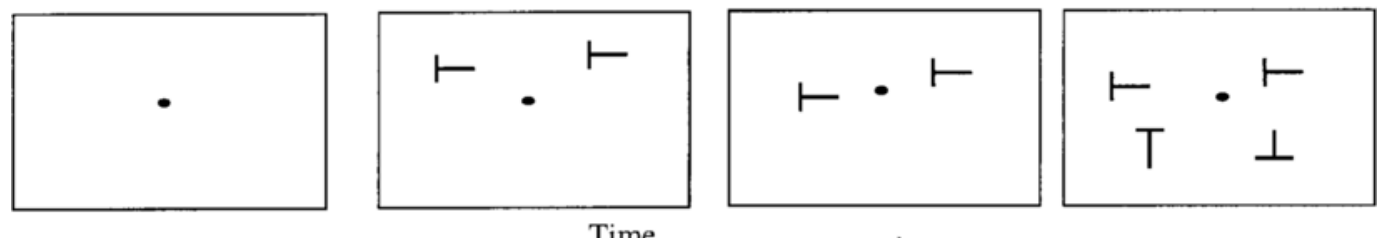

Time

Standard Preview Condition
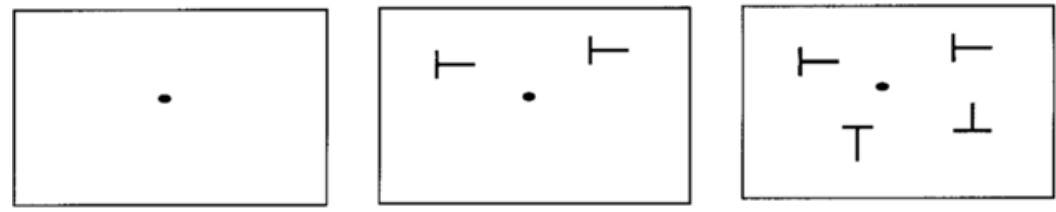

Time

Figure 1. Example displays of each condition in Experiment 1. 

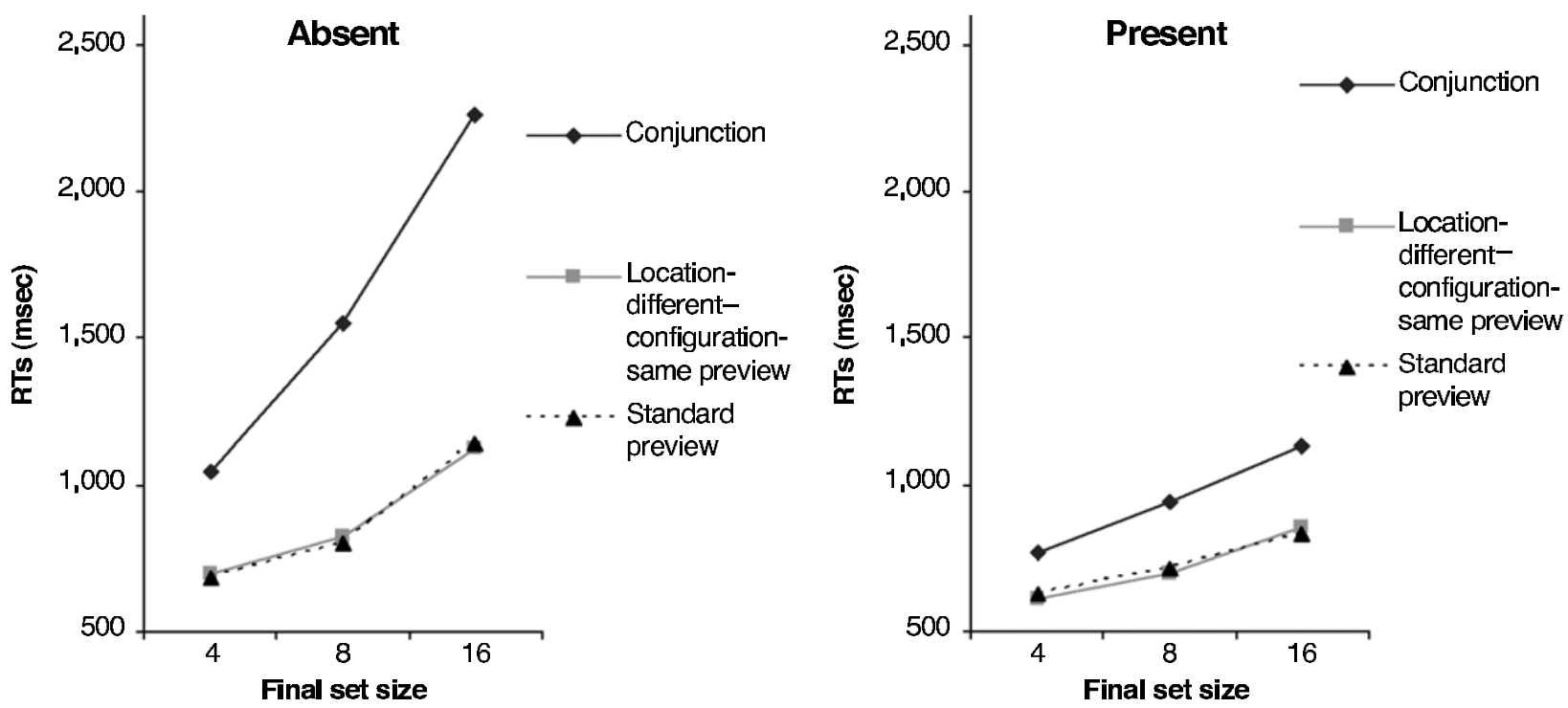

Figure 2. Mean correct response times (RTs, in milliseconds) for each condition in Experiment 1.

$80.20, p<.01]$; and RTs increased with increases in display size $[F(2,28)=172.91, p<.01]$. There were significant interactions of condition and target $[F(1,14)=40.68$, $p<.01]$, condition and display size $[F(2,28)=35.97, p<$ $.01]$, and target and display size $[F(2,28)=46.57, p<$ $.01]$. The three-way interaction between condition, target, and display size was also significant $[F(2,28)=$ $20.00, p<.01]$. Breaking down the condition $\times$ display size interaction further, we see main effects of condition at display size $4[t(29)=6.7, p<.01]$, display size 8 $[t(29)=6.9, p<.01]$, and display size $16[t(29)=6.3$, $p<.01]$.

When present trials only are considered, there were significant effects of condition $[F(1,14)=24.61, p<.01]$ and of display size $[F(2,28)=96.48, p<.01]$. There was also a significant condition $\times$ display size interaction $[F(2,28)=9.95, p<.01]$, with significant main effects at display size $4[t(14)=3.9, p<.01]$, display size $8[t(14)=$

Table 1

Percentage of Errors in the Search Conditions

Across Experiments 1-4

\begin{tabular}{|c|c|c|c|c|c|c|}
\hline \multirow[b]{3}{*}{ Condition } & \multicolumn{6}{|c|}{ Display Size } \\
\hline & \multicolumn{3}{|c|}{ Target Present } & \multicolumn{3}{|c|}{ Target Absent } \\
\hline & 4 & 8 & 16 & 4 & 8 & 16 \\
\hline \multicolumn{7}{|c|}{ Experiment 1} \\
\hline Conjunction & 3.0 & 9.3 & 9.3 & 1.0 & 1.0 & 3.7 \\
\hline LD-CS preview & 3.3 & 5.7 & 8.0 & 4.7 & 5.3 & 10.7 \\
\hline Standard preview & 3.0 & 2.7 & 12.7 & 3.7 & 4.3 & 8.3 \\
\hline \multicolumn{7}{|c|}{ Experiment 2} \\
\hline Conjunction & 7.1 & 8.6 & 10.4 & 1.1 & 1.1 & 3.9 \\
\hline LD-CS preview & 2.5 & 3.9 & 8.2 & 3.9 & 2.9 & 9.6 \\
\hline Standard preview & 2.5 & 3.6 & 8.6 & 1.4 & 1.8 & 10.7 \\
\hline \multicolumn{7}{|c|}{ Experiment 3} \\
\hline Conjunction & N/A & 6.7 & 10.6 & N/A & 0.3 & 4.7 \\
\hline LD-CS preview & N/A & 6.9 & 13.1 & N/A & 1.4 & 8.6 \\
\hline LD-CD preview & N/A & 3.6 & 9.7 & N/A & 0.8 & 8.3 \\
\hline \multicolumn{7}{|c|}{ Experiment 4} \\
\hline Conjunction & 1.8 & 1.8 & 5.3 & N/A & N/A & N/A \\
\hline LD-CS preview & 2.6 & 3.8 & 8.5 & & & \\
\hline LD-CD preview & 3.5 & 1.5 & 7.6 & N/A & $\mathrm{N} / \mathrm{A}$ & N/A \\
\hline
\end{tabular}

Note-LD-CS, location-different-configuration-same; LD-CD, location-differentconfiguration-different. 
Table 2

Descriptive Statistics for the Search Functions in Experiment 1

\begin{tabular}{|c|c|c|c|c|c|c|}
\hline \multirow[b]{2}{*}{ Condition } & \multicolumn{2}{|c|}{ Slope (msec/item) } & \multicolumn{2}{|c|}{ Intercept (msec) } & \multicolumn{2}{|c|}{$\begin{array}{l}\text { Mean Response } \\
\text { Time (msec) }\end{array}$} \\
\hline & Present & Absent & Present & Absent & Present & Absent \\
\hline Conjunction & 28.94 & 99.56 & 677 & 686 & 947 & 1,615 \\
\hline LD-CS & 20.58 & 36.10 & 529 & 544 & 721 & 881 \\
\hline Standard preview & 17.08 & 38.62 & 563 & 513 & 722 & 874 \\
\hline
\end{tabular}

Note-LD-CS, location-different-configuration same.

$4.2, p<.01]$, and display size $16[t(14)=5.5, p<.01]$. The effects of display size were smaller in the preview condition than in the conjunction baseline.

\section{Errors}

There were more errors made in the present trials, relative to the absent trials $[F(1,14)=5.27, p<.05]$, and the number of errors increased with increases in display size $[F(2,28)=41.91]$. However, there was no difference in the number of errors made between conditions $[F(2,28)=$ 3.02, n.s.], nor was there a reliable condition $\times$ display size interaction $[F(4,56)=2.27$, n.s.]. The three-way condition $\times$ target $\times$ display size interaction was not reliable $[F(4,56)=2.35$, n.s. $]$.

\section{Discussion}

Search performance was more efficient in the LD-CS preview condition than in the conjunction condition; overall RTs were reduced, and effects of display size on search were less. Indeed, there were no indications of any difference between the LD-CS preview and the standard preview conditions. Both preview conditions showed the same benefit, regardless of the fact that, in one condition, old items changed their locations and, in the other condition, they did not. The findings of a reliable preview benefit in the standard condition here replicates Olivers et al. (1999) and confirms that color differences are not necessary to produce efficient preview search. The new finding is that keeping the locations of the old items constant throughout the preview period is not necessary either, at least provided the configuration of the old items is maintained across each trial. In previous studies, it has been shown that a $300-\mathrm{msec}$ preview alone is not sufficient to produce a maximal preview benefit, ${ }^{2}$ measured relative to a standard preview baseline in which old items appear for 700 msec or longer (Watson \& Humphreys, 1997; see also Experiment 3 ). Our failure to find any evidence of a difference between the standard preview and the LD-CS preview conditions here, then, indicates that information from the first $450 \mathrm{msec}$ of the preview was used in the LD-CS condition. In Experiment 2, we tested whether the useful information carried over from the initial preview involved a configural representation of the old stimuli. To do this, we changed the configuration, as well as the locations of the old items, in a new preview change condition.

\section{EXPERIMENT 2 \\ Effects of Changing the Location and the Configuration in Shape-Defined Preview Search}

\section{Method}

\section{Participants}

Fifteen participants ( 5 males and 10 females) participated for course credit or monetary payment. Their ages ranged from 20 to 30 years (mean age, 22.9 years), and they were all taken from a population of undergraduates at the University of Birmingham. All the participants had normal or corrected-to-normal eyesight.

\section{Stimuli}

The stimuli were the same as those in Experiment 1.

\section{Design and Procedure}

There were three conditions in total: a conjunction baseline, a location-different-configuration-different preview (LD-CD), and a standard preview condition. The conjunction and standard preview conditions were the same as those in Experiment 1. In the LD-CD preview condition, a fixation dot appeared on the screen for 1,000 msec followed by upright Ts. After $450 \mathrm{msec}$, the Ts then offset and simultaneously onset again (with an ISI of $0 \mathrm{msec}$ ) in a different randomly generated position that had not been previously occupied. These items then remained on screen and were joined $300 \mathrm{msec}$ later
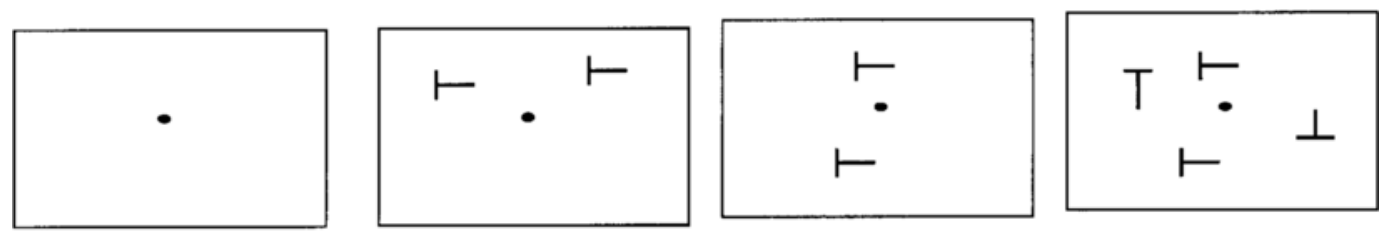

Time

Figure 3. Example display of the location-different-configuration-different preview in Experiment 2. 

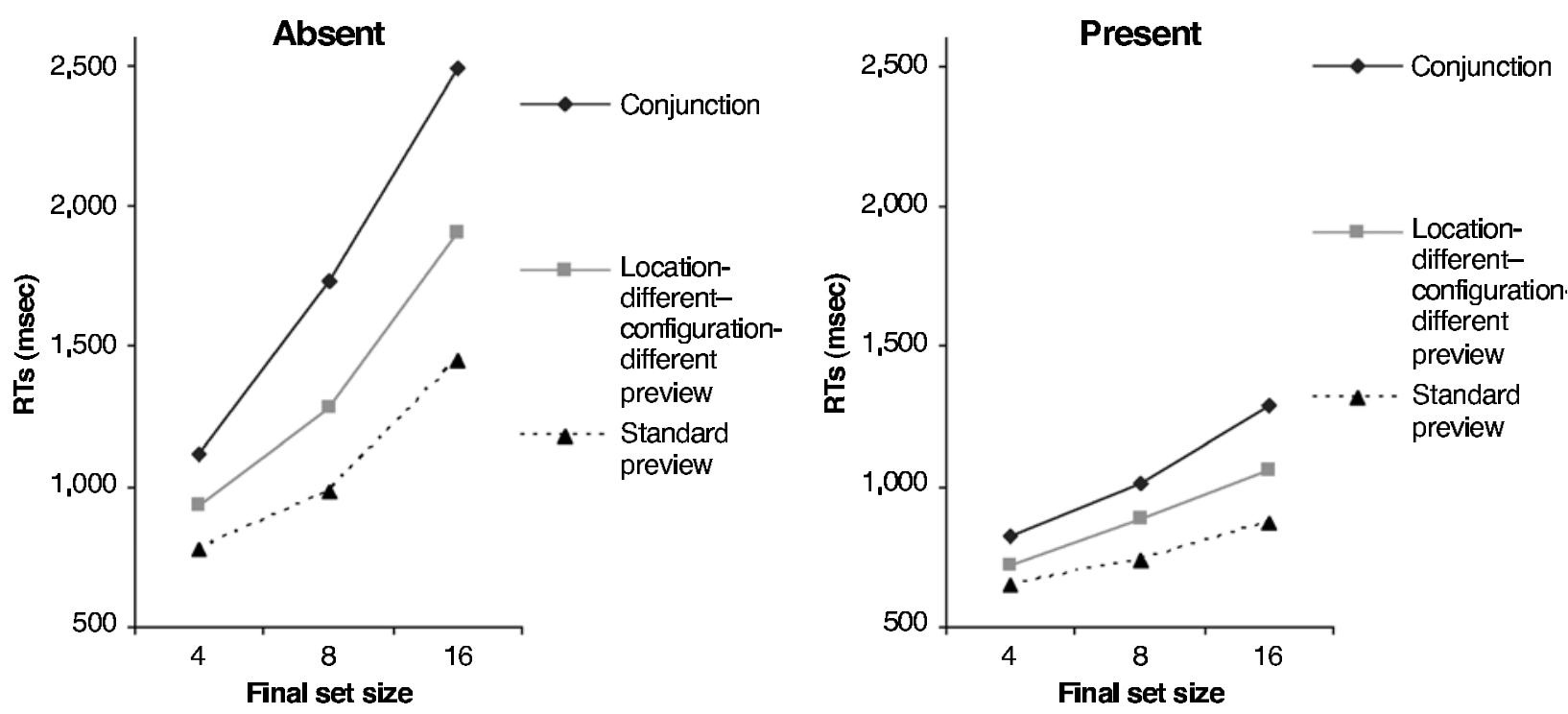

Figure 4. Mean correct response times (RTs, in milliseconds) for each condition in Experiment 2.

by rotated Ts and an inverted $\mathrm{T}$ (if present). Again, in the preview conditions, the participants were asked to keep their eyes on the fixation dot until the second set of stimuli was presented. Example displays are shown in Figure 3.

\section{Results}

Figure 4 shows the mean correct RTs as a function of display size and target presence or absence for each condition. The error rates are given in Table 1, and Table 3 shows the descriptive statistics.

\section{RTs}

Standard preview versus LD-CD preview. All three main effects were significant: RTs were faster in the standard preview than in the LD-CD preview items condition $[F(1,13)=11.14, p<.01]$; present trials were faster than absent trials $[F(1,13)=38.01, p<.01]$; and RTs increased with increases in display size $[F(2,26)=47.35$, $p<.01]$. There were also significant interactions between condition and target $[F(1,13)=6.44, p<.05]$, condition and display size $[F(2,26)=6.99, p<.01]$, and target and display size $[F(2,26)=21.21, p<.01]$. The three-way interaction between condition, target, and display size was not reliable $[F(2,26)=1.46$, n.s. $]$. Breaking down the condition $\times$ display size interaction, we see a significant effect of display size $4[t(29)=3.5, p<.01]$, display size $8[t(29)=3.8, p<.01]$, and display size $16[t(29)=3.5$, $p<.01]$. RTs were longer overall in the LD-CD preview condition, and the effects of display size were larger for this condition. This held across both absent and present trials (hence, no three-way interaction).

Conjunction versus LD-CD preview. All three main effects were significant: RTs were shorter in the LD-CD preview than in the conjunction condition $[F(1,13)=$ $14.26, p<.01]$; present trials were faster than absent ones $[F(1,13)=47.87, p<.01]$; and RTs increased with increases in display size $[F(2,26)=67.50, p<.01]$. There were also significant interactions of condition and target $[F(1,13)=8.51, p<.05]$, condition and display size $[F(2,26)=5.67, p<.01]$, target and display size $[F(2,26)=$ $28.04, p<.01]$, and condition, target, and display size $[F(2,26)=3.78, p<.05]$. Breaking down the condition $\times$ display size interaction, we see significant main effects of condition at display size $4[t(29)=4.5, p<.01]$, display size $8[t(29)=3.6, p<.01]$, and display size $16[t(29)=$ $3.8, p<.01]$.

When present trials alone are considered, the main effects of both condition $[F(1,13)=7.49, p<.05]$ and dis-

Table 3

Descriptive Statistics for the Search Functions in Experiment 2

\begin{tabular}{|c|c|c|c|c|c|c|}
\hline \multirow[b]{2}{*}{ Condition } & \multicolumn{2}{|c|}{ Slope (msec/item) } & \multicolumn{2}{|c|}{ Intercept (msec) } & \multicolumn{2}{|c|}{$\begin{array}{l}\text { Mean Response } \\
\text { Time }(\mathrm{msec})\end{array}$} \\
\hline & Present & Absent & Present & Absent & Present & Absent \\
\hline Conjunction & 38.44 & 111.41 & 683 & 741 & 1,042 & 1,781 \\
\hline LD-CD & 27.45 & 80.36 & 635 & 623 & 891 & 1,373 \\
\hline Standard preview & 17.94 & 56.36 & 585 & 542 & 753 & 1,068 \\
\hline
\end{tabular}

Note-LD-CD, location-different-configuration same. 
play size $[F(2,26)=28.44, p<.01]$ were significant. There was also a significant interaction of condition and display size $[F(2,26)=4.13, p<.05]$, with significant main effects at display size $4[t(14)=2.6, p<.05]$, display size $8[t(14)=2.1, p=.057$ (marginal) $]$, and display size $16[t(14)=2.8, p<.05]$ across conditions. The effects of display size were greater in the conjunction condition than in the LD-CD preview condition.

Conjunction versus standard preview. All three main effects were significant: RTs were shorter in the preview than in the conjunction condition $[F(1,13)=44.68, p<$ $.01]$; present trials were faster than absent ones $[F(1,13)=$ $49.73, p<.01]$; and RTs increased with increases in display size $[F(2,26)=83.41, p<.01]$. All the interactions were significant: condition $\times$ target $[F(1,26)=29.46$, $p<.01]$, condition $\times$ display size $[F(2,26)=22.71, p<$ $.01]$, target $\times$ display size $[F(2,26)=50.11, p<.01]$, and condition $\times$ target $\times$ display size $[F(2,26)=10.45, p<$ $.01]$. Breaking down the condition $\times$ display size interaction, we see significant main effects of condition at display size $4[t(29)=5.8, p<.01]$, display size $8[t(29)=$ $5.8, p<.01]$, and display size $16[t(29)=6.1, p<.01]$.

When present trials only are considered, there were significant effects of condition $[F(1,13)=27.72, p<.01]$ and of display size $[F(2,26)=37.21, p<.01]$. There was also a significant condition $\times$ display size interaction $[F(2,26)=8.08, p<.01]$, with significant main effects at display size $4[t(14)=4.3, p<.01]$, display size $8[t(14)=$ $3.9, p<.01]$, and display size $16[t(14)=4.2, p<.01]$ across conditions. The effects of display size were smaller in the preview than in the conjunction baseline condition.

\section{Errors}

Errors increased with increases in display size $[F(2,26)=$ $24.47, p<.01]$; however, there was no difference in the number of errors made between conditions $[F(2,26)=$ 0.22 , n.s. $]$ or between present and absent trials $[F(1,13)=$ 3.63 , n.s.]. Nor was the three-way condition $\times$ target $\times$ display size interaction reliable $[F(4,52)=0.43$, n.s.]. The condition $\times$ display size interaction just reached significance $[F(4,52)=2.59, p=.047]$. Breaking this interaction down between conditions, we see that this result was due to more errors being made in the conjunction condition, relative to the standard preview condition $[F(2,26)=$ $3.98, p<.05] . .^{3}$ None of the other comparisons of the condition $\times$ display size interaction reached significance.

\section{Discussion}

The results in the novel LD-CD preview condition contrast with those observed in the LD-CS preview condition in Experiment 1; that is, there appears to be some detrimental effect of changing the configuration of the old stimuli on preview search. Here, when the configuration changed (in the LD-CD condition), performance was reliably worse than the standard preview baseline, and it was affected more by the presence of distractors. This cost in the preview benefit in the $\mathrm{LC}-\mathrm{CD}$ condition suggests that configural information is a useful cue, enabling search to become more efficient. If configural properties are maintained across a trial (the conditionLC-CS in Experiment 1), search is more efficient than when this information is lost (the condition LC-CD in Experiment 2), as compared with a standard preview condition. Despite this, performance in the LD-CD condition was better than that in the conjunction baseline condition. However, that benefit may be due to the 300 -msec preview that occurred prior to the new search displays. Prior studies have reported a partial (suboptimal) preview effect with a preview duration of $300 \mathrm{msec}$ or so (Watson \& Humphreys, 1997). To provide a stronger test of our conjecture that configuration change affects performance, we conducted Experiment 3 , in which we evaluated the effects of configuration change in a within-subjects design. We also compared these conditions with a standard preview condition in which the old items appeared for only $300 \mathrm{msec}$. This condition allowed us to investigate what influence the prior 450 -msec presentation of the old items would have on preview search and whether its encoded configural properties would affect search.

\section{EXPERIMENT 3 \\ A Direct Comparison of the Effects of Configuration Change in Shape-Defined Preview Search and of a 300-msec Preview Condition}

In Experiment 3, the participants received both the LDCS and the LD-CD preview conditions, to provide a direct comparison of the effects of configuration change across conditions when the old items moved. Performance was also measured relative to a standard preview condition in which the old items appeared only for $300 \mathrm{msec}$. Previous research has shown that a $300-\mathrm{msec}$ preview of old items alone is not sufficient to provide a full preview benefit (Watson \& Humphreys, 1997; see also note 2). This baseline condition provided a reference to see whether information from the initial configuration of the preview items would be carried over to aid efficient search. If so, we would expect the LD-CS preview condition to show a bigger preview benefit, relative to the 300 -msec preview condition (since configural information would be retained across search), whereas the preview benefit in the LD-CD condition might not be more efficient than that in the 300msec preview condition, since the previous configural (and location) cues were disrupted.

\section{Method}

\section{Participants}

Thirteen participants ( 3 males and 10 females) participated for course credit or monetary payment. Their ages ranged from 20 to 27 years (mean age, 23.6 years), and they were all taken from a population of undergraduates at the University of Birmingham. All the participants had normal or corrected-to-normal eyesight.

\section{Stimuli}

The stimuli were the same as those in Experiments 1 and 2. However, in this case, only display sizes of 8 and 16 were used, since this should produce an adequate replication of the findings in Experi- 
ments 1 and 2, in an efficient manner, by decreasing the time constraints on each participant.

\section{Design and Procedure}

There were three conditions: a standard preview condition in which the old items were presented for $300 \mathrm{msec}$ before the onset of the new items, the LD-CS preview, and the LD-CD preview. The conditions were blocked and were presented in a counterbalanced order across participants.

\section{Results}

Figure 5 shows the mean correct RTs as a function of display size and target presence or absence for each condition. The error rates are given in Table 1 .

\section{RTs}

300-msec preview versus LD-CS preview. All three main effects were significant: RTs were marginally shorter in the LD-CS condition than in the 300-msec preview condition $[F(1,12)=4.63, p=.052]$; present trials were faster than absent ones $[F(1,12)=9.46, p=.01]$; and RTs increased with increases in display size $[F(1,12)=21.54$, $p<.01]$. There were also significant interactions of condition and display size $[F(1,12)=6.04, p<.05]$ and of target and display size $[F(1,12)=15.52, p<.01]$, but not of condition and target $[F(1,12)=1.88$, n.s.]. The threeway interaction between condition, target, and display size also was not reliable $[F(1,12)=2.83$, n.s.]. Breaking down the condition $\times$ display size interaction, we see main effects of condition at display size $4[t(25)=3.6$, $p<.01]$, display size $8[t(25)=2.1, p<.05]$, and display size $16[t(25)=2.5, p<.05]$. Overall, RTs were shorter in the LD-CS condition than in the 300-msec preview condition, and RTs in the LD-CS preview were less affected by the display size.

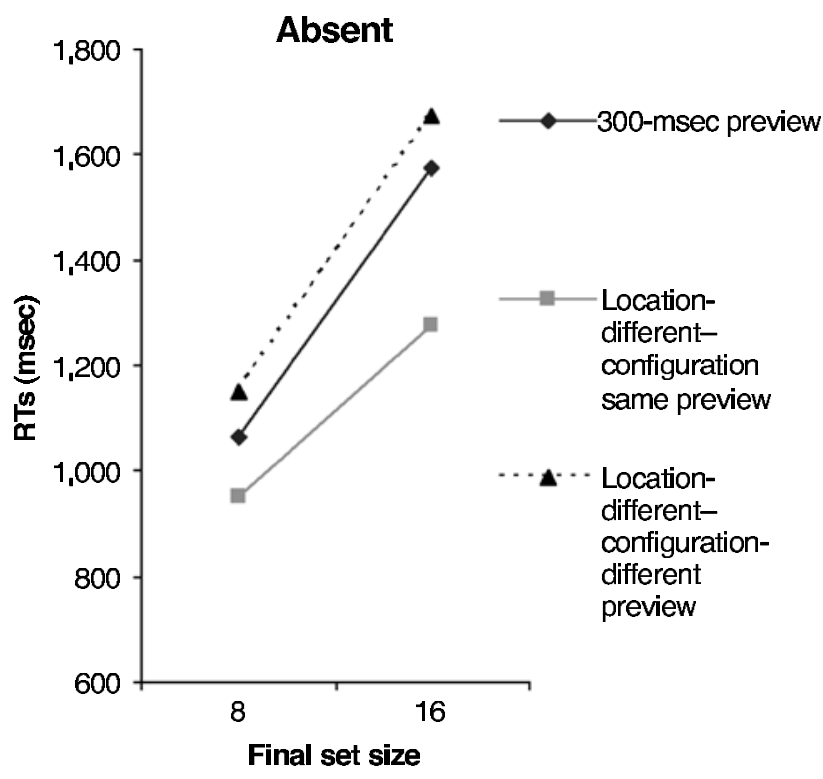

300-msec preview versus LD-CD preview. Present trials were faster than absent ones $[F(1,12)=11.30, p<$ $.01]$, and RTs increased with increases in display size $[F(1,12)=18.39, p<.01]$. However, there was no main effect of condition $[F(1,12)=0.80$, n.s.]. There was a significant interaction of target and display size $[F(1,12)=$ $20.56, p<.01]$, but not of condition and target $[F(1,12)=$ 0.84 , n.s.], or of condition and display size $[F(1,12)=$ 0.38 , n.s.]. The three-way interaction between condition, target, and display size also failed to reach significance $[F(1,12)=0.17$, n.s. $]$. The effects of display size did not differ across the conditions.

LD-CS preview versus LD-CD preview. All three main effects were significant: RTs were shorter in the LD-CS preview than in the LD-CD preview condition $[F(1,12)=7.11, p<.05]$; present trials were faster than absent ones $[F(1,12)=14.83, p<.01]$; and RTs increased with increases in display size $[F(1,12)=16.95, p<.01]$. There were significant two-way interactions between condition and target $[F(1,12)=5.45, p<.05]$, condition and display size $[F(1,12)=5.22, p<.05]$, and target and display size $[F(1,12)=31.59, p<.01]$. The three-way interaction between condition, target, and display size was not significant $[F(1,12)=1.35$, n.s.]. Breaking down the condition $\times$ display size interaction, we see main effects of condition at display size $4[t(25)=3.5, p<.01]$, display size $8[t(25)=3.3, p<.01]$, and display size $16[t(25)=$ $3.0, p<.01]$. Overall, there was a RT advantage when the configuration did not change (in LD-CS), and RTs in this condition were less affected by display size.

\section{Errors}

Errors increased with increases in display size $[F(1,12)=$ $57.06, p<.01]$; however, there was no difference in the

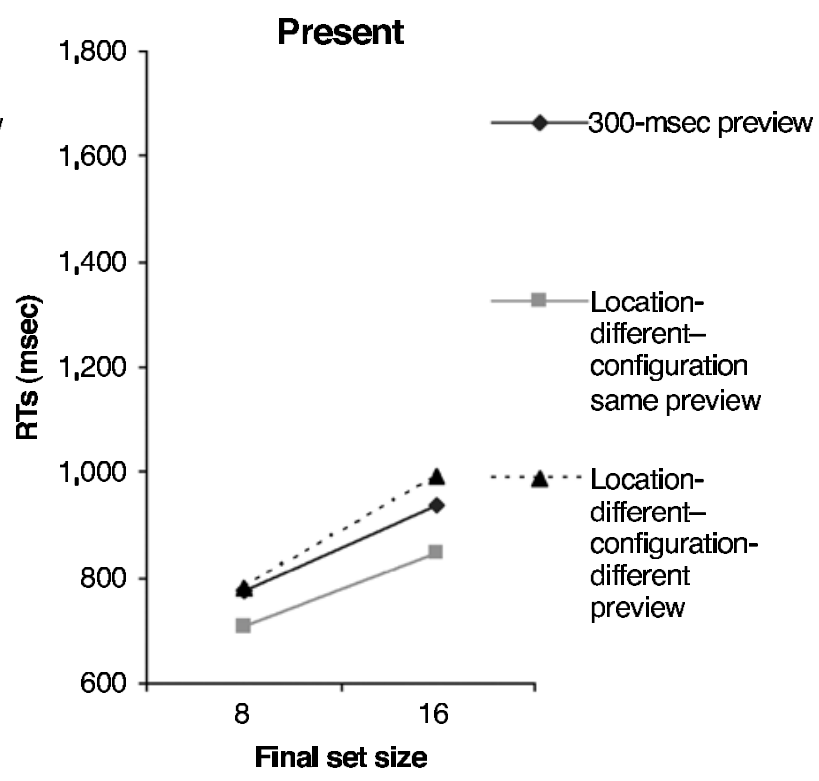

Figure 5. Mean correct response times (RTs, in milliseconds) for each condition in Experiment 3. 
number of errors made between conditions $[F(2,24)=$ 0.68$, n.s. $]$ or between present and absent trials $[F(1,12)=$ 0.17 , n.s.]. Nor did any of the two-way interactions or the three-way interaction reach significance.

\section{Discussion}

The data replicated those in Experiments 1 and 2. Performance was relatively more efficient when the configuration of the old items remained the same across the preview search (the LD-CS condition) than when the configuration changed (the LD-CD condition). This again indicates that the configuration of the old items was a useful cue in providing an efficient preview benefit. One opposing account to this view is that the LD-CS condition may have been more efficient, in terms of the preview benefit, because the overall displacement of the old items was less on a trial-by-trial basis than the displacement found in the LD-CD condition. However, we do not think this to be the case. In another two subexperiments, we have found that if the displacement of the old items in the LD-CD condition was matched to that in the LD-CS condition, the LD-CS condition still showed a greater preview benefit than did the LD-CD condition when compared with a standard preview condition. ${ }^{4}$ The fact that these results mimicked those found in Experiments 1 and 2 indicates that the distance the old items were displaced was not critical; rather, the LD-CS condition was more efficient because the configural representation of the old items had been encoded and used to segment old and new stimuli in search.

A further interesting finding was the variation in performance relative to the $300-\mathrm{msec}$ preview condition. In particular, the LC-CS preview was more efficient than the 300-msec preview, whereas the LC-CD condition was not. This result again indicates that having a $450-\mathrm{msec}$ preview of the old items is sufficient to enhance search only if the old items retain their configuration across a trial. If the configuration is disrupted, it seems that there is no carry-over of residual information and search is on a par with the $300-\mathrm{msec}$ preview condition, in which no prior appearance of the old items occurs.

In the final experiment (Experiment 4), we investigated whether configuration effects would be apparent when the new and the old items differed in color as well as shape. As we noted in the introduction, previous studies of preview search with static displays have indicated that color carry-over effects can be found; stimuli that have the same color as preview displays have reduced impact on search (Olivers \& Humphreys, 2003). On the other hand, changing the color of static items does not disrupt the preview benefit (Watson \& Humphreys, 2002). These results suggest that color-based inhibition of old items may contribute to preview search (as is shown by the color carryover effects) but that other means of prioritizing new items remain even when color change takes place (e.g., locationor configuration-based inhibition). To test whether configuration effects are important when color segmentation of old and new stimuli is possible, we used color-form conjunction targets here. As in Experiments 1-3, preview items appeared for $450 \mathrm{msec}$ and then moved to new lo- cations, where they remained for $300 \mathrm{msec}$ prior to the presentation of the search displays. In one case, the items maintained the same configuration across this change (the LDCS condition), and in another the configuration was altered (the LD-CD condition). However, in this study, the old items were green $\mathrm{Hs}$, and the new letters were blue A distractors and a blue H target (see Watson \& Humphreys, 1997). Performance was compared against a conjunction baseline.

\section{EXPERIMENT 4 \\ A Direct Comparison of the Effects of Configuration Change in Segmented Color Preview Search}

\section{Method}

\section{Participants}

Eighteen participants (5 males and 13 females) took part for of course credit or monetary payment. Their ages ranged from 18 to 37 years (mean age, 23.0 years), and they were all taken from a population of undergraduates at the University of Birmingham. All the participants had normal or corrected-to-normal eyesight.

\section{Stimuli}

The target was a blue $\mathrm{H}$, and the distractors were green $\mathrm{Hs}$ and blue As. The letters subtended a visual angle of $0.4^{\circ} \times 0.8^{\circ}$ at an observation distance of $60 \mathrm{~cm}$. In order to maximize the number of trials of maximum interest, the target was always present. ${ }^{5}$ The task was to decide whether the bar of the blue $\mathrm{H}$ was higher than the midpoint of the $y$-axis or lower than the midpoint. Half the green $\mathrm{H}$ distractors also had bars in a position above the vertical midpoint, and half below it, in order to preserve conjunction conditions. Previous studies in which these stimuli were used have shown that the relationships between the search slopes of the single feature, conjunction, and standard preview conditions were the same as those found by Watson and Humphreys (1997); that is, the preview slope was the same as the single feature baseline but was different from the conjunction (see Kunar, Humphreys, \& Smith, 2003; Kunar, Humphreys, Smith, \& Watson, 2003).

There were three conditions: a conjunction baseline, a preview in which the locations of the old items changed but the configuration stayed the same (the LD-CS condition), and a preview in which the locations and the configuration of the old stimuli changed (the LD-CD condition). The experimental blocks each contained 60 trials (20 per display size), and the order of the blocks was counterbalanced across participants (see Figure 6 for example displays).

\section{Design and Procedure}

In the conjunction search, a fixation dot appeared on the screen for 1,000 msec followed by green $\mathrm{Hs}$, blue As, and a blue $\mathrm{H}$. The participants were asked to respond using the " $\mathrm{m}$ " and " $\mathrm{z}$ " keys according to whether the bar of the blue $\mathrm{H}$ was high or low. Response keys were counterbalanced across the experiment. In the LD-CS preview condition, a fixation dot again appeared for 1,000 $\mathrm{msec}$ before green Hs were added. After $450 \mathrm{msec}$, the green $\mathrm{Hs}$ were then vertically displaced one visual degree downward and remained in this position for $300 \mathrm{msec}$ before blue items were added to the display. In the LD$\mathrm{CD}$ preview condition, the procedure was the same, except that the old items appeared in randomly generated positions (not previously occupied) for $300 \mathrm{msec}$, after holding their initial positions for $450 \mathrm{msec}$. In the preview conditions, the participants were asked to keep their eyes on the fixation dot until the blue items appeared and, only then, to begin their search.

\section{Results}

One participant was dropped from analysis due to high errors (some as high as $25 \%$ ). Figure 7 shows the mean correct RTs as a function of the display size for each con- 


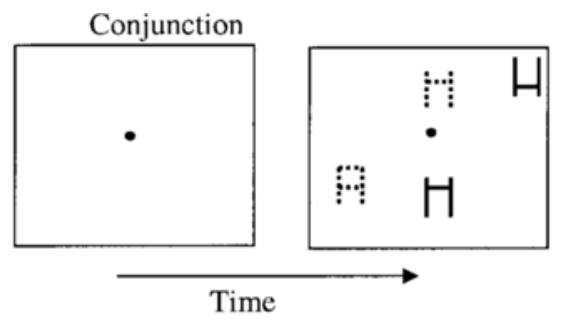

Location-different-configuration-same preview

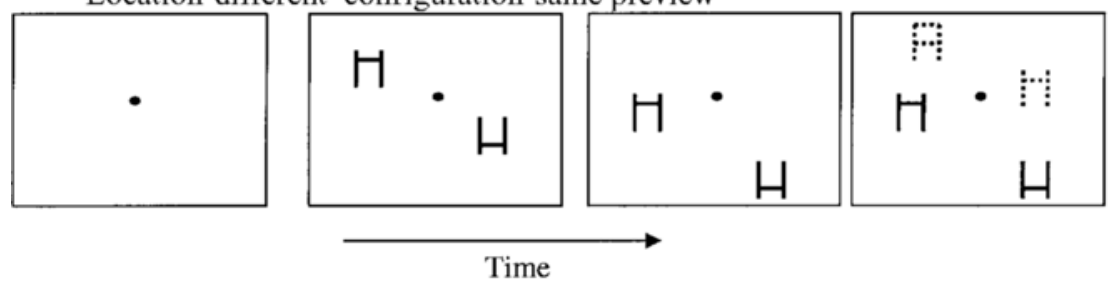

Location-different-configuration-different preview

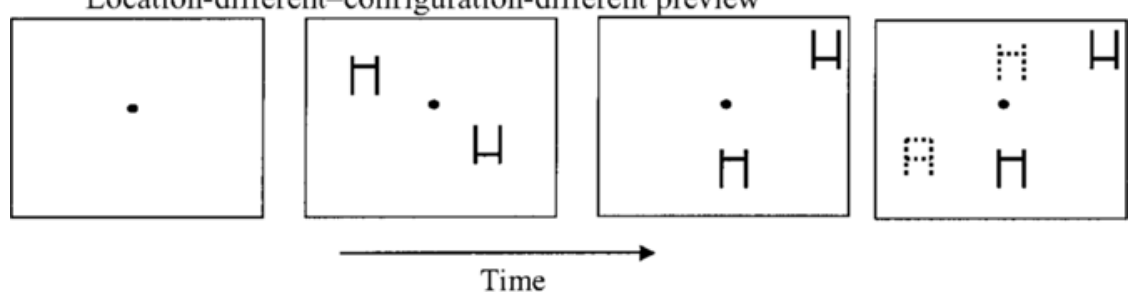

Figure 6. Example displays of each condition in Experiment 4.

dition. The error rates are given in Table 1, and Table 4 shows the descriptive statistics.

\section{RTs}

Conjunction versus LD-CS preview. RTs were shorter in the LD-CS preview condition than in the conjunction baseline $[F(1,16)=23.59, p<.01]$, and RTs overall increased with increases in display size $[F(2,32)=$ $144.43, p<.01]$. There was also a significant interaction between condition and display size $[F(2,32)=21.24, p<$ $.01]$. This effect was especially apparent at the larger display sizes of $8[t(16)=3.1, p<.01]$ and $16[t(16)=5.8$, $p<.01]$, although it failed to reach significance at display size 4 . The effects of display size were larger for the conjunction baseline than for the LD-CS preview condition. ${ }^{6}$

Conjunction versus LD-CD preview. RTs increased with increases in display size $[F(2,32)=159.89, p<.01]$, but there was no significant main effect between the conditions $[F(1,16)=2.98$, n.s. $]$. There was, however, a significant interaction between condition and display size $[F(2,32)=7.10, p<.01]$ and a main effect of condition at display size $16[t(16)=2.3, p<.05]$. The effects of display size were larger for the conjunction than for the LD-CD preview.

Comparison of the preview conditions. RTs increased with increases in display size $[F(2,32)=79.40, p<.01]$, but there was no significant difference between conditions $[F(1,16)=2.99$, n.s. $]$. However, there was a significant interaction between condition and display size $[F(2,32)=$ $3.59, p<.05]$ and a main effect of condition at display size $16[t(16)=2.2, p<.05]$. The effects of display size were larger when the configuration of the preview changed (LD-CD), relative to when it stayed the same (LD-CS).

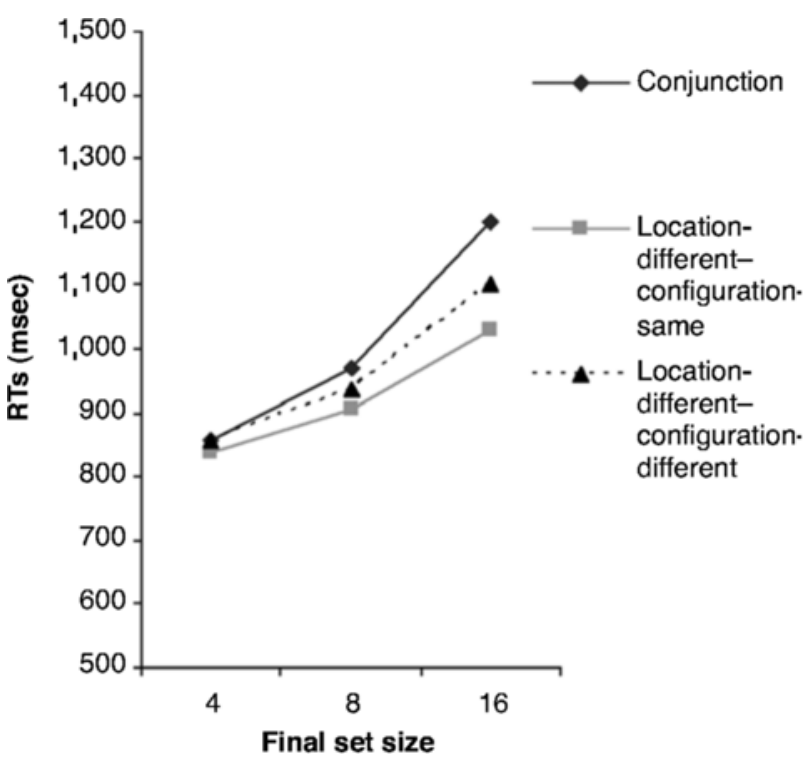

Figure 7. Mean correct response times (RTs, in milliseconds) for each condition in Experiment 4. 
Table 4

Descriptive Statistics for the Search Functions in Experiment 4

\begin{tabular}{lccc}
\hline \multicolumn{1}{c}{ Condition } & Slope $(\mathrm{msec} /$ item $)$ & Intercept $(\mathrm{msec})$ & Mean RT $(\mathrm{msec})$ \\
\hline Conjunction & 28.29 & 745 & 1,009 \\
LD-CS preview & 15.81 & 777 & 924 \\
LD-CD preview & 20.26 & 776 & 965 \\
\hline
\end{tabular}

Note-LD-CS, location-different-configuration-same; LD-CD, location-

different-configuration-different.

\section{Errors}

Errors increased with increases in display size $[F(2,32)=$ $22.45, p<.01]$; however, there was no reliable difference in the number of errors made between conditions $[F(2,32)=$ $3.26, p=$ n.s.], nor was the condition $\times$ display size interaction reliable $[F(4,64)=1.10$, n.s. $]$.

\section{Discussion}

The results are similar to the findings with form-based search in Experiments 1-3. Performance was more efficient when the preview display maintained its configuration, relative to when the configuration was altered (in the LD-CS condition relative to the LD-CD condition). There were also benefits for both preview conditions when compared with the conjunction baseline. Thus, even when the configuration changed, presenting half the distractors before the new search set facilitated performance (in the LDCD condition). As has already been noted, this could be due to the 300-msec preview in which the items remained in the same location prior to the search display. More important, the benefit in this condition was enhanced when the configuration of the old items was constant. This provides positive evidence for configural effects on preview search even when the old and the new items differed in color. If color alone mediated the preview effect here, no influence of the configuration would be expected. Our data, then, are consistent with the argument that factors other than color-based inhibition contribute to the preview benefit with static items. One other factor is the configuration of the old elements, which may be inhibited to enhance the preview benefit. Indeed, note that the search slope in the LD-CS condition was about half that in the conjunction baseline. This suggests that the participants could restrict their search to just the new items in these displays. It follows that configural-based VM may be sufficient to generate a maximal preview effect, even when the locations of the stimuli change.

\section{GENERAL DISCUSSION}

We have reported four experiments that have demonstrated evidence for configural effects in preview search. In Experiments 1-3, we examined search for within-form conjunctions (an inverted $\mathrm{T}$ target among rotated and upright $\mathrm{T}$ distractors). In the critical conditions, preview items appeared for $450 \mathrm{msec}$ and then changed their locations while the overall configuration was either maintained or altered. The preview stimuli then remained stationary for a further $300 \mathrm{msec}$, when the new stimuli were added to the displays. When the configuration was maintained, performance was as efficient as in a standard preview condition, in which the old items stayed stationary for $750 \mathrm{msec}$. When the configuration changed, search was less efficient, although some benefits were still apparent relative to a conjunction baseline condition (in which all the items appeared simultaneously). This slight preview benefit was probably a result of the 300-msec preview period that followed the configural change of the old items (Experiment 3). Similar effects were found in Experiment 4, in which the old and the new items differed in color. The results demonstrated that a configural representation of the old items is encoded and used to help segment old from new items, to facilitate search.

\section{Accounts of Preview Search}

The data can be used to distinguish between different accounts of the preview benefit. In particular, they indicate that the representation of old items is important for search and that performance cannot be attributed simply to attention capture by new items (cf. Donk \& Theeuwes, 2001). Donk and Theeuwes argued that the preview benefit is critically dependent on the detection of luminance increments with the onset of new items. They found that items appearing with no luminance onset do not produce a preview benefit. The experiments reported above, however, suggest that luminance change, caused by the onset of the new items, is not sufficient to elicit a preview advantage. In both the configuration-same condition and the configuration-differentcondition, new items were separated from the old items (in their new locations) by $300 \mathrm{msec}$. Yantis and Gibson (1994) found that $100 \mathrm{msec}$ was enough time to allow new items to be temporally segregated from old and, thus, capture attention when they onset. If onset capture were entirely responsible for the preview effect, we would have expected both configural conditions to have shown the same search advantage. Since they did not, we can only assume that configural representations of the old items encoded in the 450 -msec preview prior to the location change of the old items were carried over and used to aid search.

Similarly, the data are not entirely consistent with the temporal-grouping account (Jiang et al., 2002). Jiang et al. clearly stated that changes that are not synchronized with the onset of new items are deemed unimportant and should not affect preview search. This occurs even if changes to old items are made $107 \mathrm{msec}$ before the onset of the new. 
Here, they claim that "because such changes are not synchronized with the onset of the new items, the two sets of items remain segregated" (Jiang et al., 2002, p. 728) and that this generates effective preview search. However, we found that asynchronous changes to old items (i.e., the changes to the old configuration) occurring before the onset of new items did disrupt preview search. Moreover, the temporal parameters of any changes were the same in the configuration-same and the configuration-different conditions. A temporal-grouping account alone would predict similar performance in both conditions. ${ }^{7}$ Nevertheless, despite these problems, a grouping account may in part explain the results if we view the data in terms of grouping by coherent motion. In the configuration-same condition, items could still be grouped by coherent motion, but not in the configuration-different condition; this form of grouping could have benefited search.

The data are also consistent with an explanation in terms of VM, involving the inhibitory rejection of old distractors, if we include one additional factor that can be used in segregating old from new stimuli: the spatial configuration of the old items. Here, we propose that the configural coding of the old distractors enables them to be rejected more easily from search. The results also indicate that the configural representation of the old distractors is carried over across local movements of the individual stimuli. Note that this is likely to be useful in the real world, where elements in a scene might undergo some transient change. Maintaining VM across this change would be appropriate if the elements retain the same configuration and are likely to represent a single old object. Configural coding can provide a way of rejecting old distractors as a single group. It is also possible that other forms of grouping could contribute too, including grouping by color and grouping by temporal onsets (as was suggested by Jiang et al., 2002). In fact, temporal grouping seems important in explaining why preview effects are abolished when old items offset and then reappear along with new stimuli (in the "blink" condition examined by Kunar, Humphreys, Smith, \& Watson, 2003, and Watson \& Humphreys, 1997). It is only when this grouping is disrupted by the top-up procedure (see Kunar, Humphreys, \& Smith, 2003) that we see the influence of the representation of old items on performance. Configural grouping could combine with other forms of grouping to facilitate the inhibition of old stimuli. Future work needs to assess whether these different forms of grouping combine in a linear or a nonlinear fashion.

One final hypothesis suggests that the status of previewed items as either old or new may determine the preview effect. Consider the results presented here. The LDCS condition may show a greater preview effect as old items move together as a specific object on a surface and, thus, retain their identity as old items, only in a slightly different position. On the other hand, old items in the LD$\mathrm{CD}$ condition move randomly and, thus, may be perceived as new items when they reach their new positions. In this case, the new previewed items in the LC-CD condition will not retain their initial inhibition and will thus have to be re-marked. Note that in this case, although the status of the previewed items may have changed from old to new, they may still have to undergo inhibitory filtering in order to be rejected as competitive items in visual search.

\section{Inhibitory "Routes" in VM}

In their original paper, Watson and Humphreys (1997) proposed that VM was based on inhibition of the locations of old distractors. We found no evidence for this. In Experiment 1, the old items moved their location in the LD-CS condition, but provided the configuration of the elements was constant, performance was as good as when the old items stayed in the same positions throughout (in the standard preview condition). This was not due to the 300 -msec preview that occurred prior to the new items. Previous studies have shown that such short previews do not benefit search as much as the "standard" preview of $750 \mathrm{msec}$ used here (Watson \& Humphreys, 1997). In addition, the 300-msec preview was not so effective when the configuration of the old items changed (in the LD-CD condition). We conclude that the location change of the old stimuli had no effect on performance. Does this mean that location-based inhibition does not take place? The strongest evidence to date for location-based inhibition comes from studies in which the probe-dot procedure was used, which have demonstrated inefficient processing of probes that fall at the locations of old stimuli (Olivers \& Humphreys, 2002; Watson \& Humphreys, 2000). It could be, however, that there is inhibition of the locations occupied by the configuration of the old items. When the configuration moves (e.g., as in the LD-CS condition), some more abstract configural template may be maintained that enables the inhibition to shift with the old items to the new locations. As a consequence, the old items are still rejected efficiently, generating a maximal preview benefit (see Watson, 2001).

A somewhat different view is that there are independent forms of VM applied to old items. This may involve inhibition of locations of the stimuli in the visual field, inhibition of their spatial configuration (as here), and also inhibition of their common color (in a color map; see Olivers \& Humphreys, 2003, for evidence). Provided at least one form of VM is maintained across a change in the stimulus, a preview benefit would be found. Also, since any simple means of inhibiting old distractors from search will mean efficient selection of new stimuli, we may not expect there to be additional benefits when more than one factor is present (e.g., as in Watson \& Humphreys, 1997, when the old items maintained their locations, their configuration, and their color). Each form of VM, however, may be reset by dynamic change to the shape of the stimulus. Watson and Humphreys (2002) found that dynamic changes to the shape of old items abolished the preview effect.

\section{The Relations of VM to Other Mechanisms of Selection}

Although it has been argued that VM is distinct from other visual search mechanisms (see Watson \& Humphreys, 
1997, and Olivers, Humphreys, Heinke, \& Cooper, 2002, for details), it may, in some ways, be similar to inhibition of return (IOR) in terms of "what" has become inhibited. Olivers, Humphreys, Heinke, and Cooper (2002) rejected the idea that marking was contingent on serial IOR of each item in the preview. They had participants search each item in a preview and, in fact, showed that these items were difficult to exclude from search when the new items appeared. Nevertheless, IOR may not be a unitary mechanism. Indeed, there is evidence for both location-based and object-based IOR, which may combine additively to affect performance (Tipper, Driver, \& Weaver, 1991). Although different from serial location-based IOR (Olivers et al., 2002), it may be possible that configuration-dependent VM is similar to object-based IOR. Thus, both VM IOR and object-based IOR take some time to be established (cf. Watson \& Humphreys, 1997, with Tipper et al., 1991), and both can be maintained across transient changes to old items (e.g., movements across the visual field). It is for future work, perhaps utilizing techniques from cognitive neuroscience, to evaluate whether these specific mechanisms of visual selection differ.

\section{Implications for "Amnesic" Search}

Horowitz and Wolfe (1998) conducted an experiment whereby they randomly repositioned letters in a visual search task every $111 \mathrm{msec}$. They found that, despite these constant relocation changes, search efficiency was not impaired in comparison with a static search task in which items remained stationary. Horowitz and Wolfe claimed that this was evidence for an "amnesic" search process, which relies on ranking the salience of each item at each given moment. In this search procedure, the most salient item at one particular point will guide attention toward it. If this item is not the target, the next salient target will be searched. However fluctuating noise in the ranking system causes the saliency of each item to be constantly updated, so that different items are searched first at any given point. This search strategy would be the same independently of whether items move or not, since it is not reliant on the memory of the previous representations of the distractor items. In contrast to these conclusions, the data here suggest that participants can use a memory template for the positions of old items in search and that this contributes to efficient performance in the configurationsame condition. Whether this memory representation is used in serial search (as in Horowitz \& Wolfe, 1998) needs to be analyzed in future work.

\section{REFERENCES}

Chun, M. M., \& Wolfe, J. M. (1996). Just say no: How are visual search trials terminated when there is no target present? Cognitive Psychology, 10, 39-78.

Donk, M., \& Theeuwes, J. (2001). Visual marking beside the mark: Prioritizing selection by abrupt onsets. Perception \& Psychophysics, 63, 891-900.

GiBSON, B. S., \& JIANG, Y. (2001). Visual marking and the perception of salience in visual search. Perception \& Psychophysics, 63, 59-73.

Horowitz, T. S., \& WolfE, J. M. (1998). Visual search has no memory. Nature, 394, 575-577.
JiAng, Y., \& Chun, M. M. (2001). Selective attention modulates implicit learning. Quarterly Journal of Experimental Psychology, 54A, 1105-1124.

JiAng, Y., Chun, M. M., \& Marks, L. E. (2002). Visual marking: Selective attention to asynchronous temporal groups. Journal of Experimental Psychology: Human Perception \& Performance, 28, 717-730.

Kunar, M. A., Humphreys, G. W., \& Smith, K. J. (2003). History matters: The preview benefit in search is not onset capture. Psychological Science, 14, 181-185.

Kunar, M. A., Humphreys, G. W., \& Smith, K. J. (in press). Visual change with moving displays: More evidence for color feature map inhibition during preview search. Journal of Experimental Psychology: Human Perception \& Performance.

Kunar, M. A., Humphreys, G. W., Smith, K. J., \& Watson, D. G. (2003). When a re-appearance is old news: Visual marking survives occlusion. Journal of Experimental Psychology: Human Perception \& Performance, 29, 185-198.

Olivers, C. N. L., \& Humphreys, G. W. (2002). Visual marking under attentional blink conditions: More evidence for top-down limited capacity inhibition. Journal of Experimental Psychology: Human Perception \& Performance, 28, 22-42.

Olivers, C. N. L., \& Humphreys, G. W. (2003). Visual marking inhibits singleton capture. Cognitive Psychology, 47, 1-42.

Olivers, C. N. L., Humphreys, G. W., Heinke, D., \& Cooper, A. C. G. (2002). Prioritization in visual search: Visual marking is not dependent on a mnemonic search. Perception \& Psychophysics, 64, 540560 .

Olivers, C. N. L., Watson, D. G., \& Humphreys, G. W. (1999). Visual marking of locations and feature maps: Evidence from within-dimension defined conjunctions. Quarterly Journal of Experimental Psychology, 52A, 679-715.

Theeuwes, J. (1992). Perceptual selectivity for color and form. Perception \& Psychophysics, 51, 599-606.

Theeuwes, J., Kramer, A F., \& Atchley, P. (1998). Visual marking of old objects. Psychonomic Bulletin \& Review, 5, 130-134.

Tipper, S. P., Driver, J., \& Weaver, B. (1991). Object-centered inhibition of return of visual attention. Quarterly Journal of Experimental Psychology, 43A, 289-298.

Treisman, A., \& Sato, S. (1990). Conjunction search revisited. Journal of Experimental Psychology: Human Perception \& Performance, 16, 459-478.

Watson, D. G. (2001). Visual marking in moving displays: Featurebased inhibition is not necessary. Perception \& Psychophysics, 63, 7484.

Watson, D. G., \& Humphreys, G. W. (1997). Visual marking: Prioritizing selection for new objects by top-down attentional inhibition of old objects. Psychological Review, 104, 90-122.

Watson, D. G., \& Humphreys, G. W. (1998). Visual marking of moving objects: A role for top-down feature based inhibition in selection. Journal of Experimental Psychology: Human Perception \& Performance, 3, 1-17.

Watson, D. G., \& Humphreys, G. W. (2000). Visual marking: Evidence for inhibition using a probe-dot detection paradigm. Perception \& Psychophysics, 62, 471-481.

Watson, D. G., \& Humphreys, G. W. (2002). Visual marking and visual change. Journal of Experimental Psychology: Human Perception \& Performance, 3, 379-395.

YAntis, S., \& GiBson, B. (1994). Object continuity in apparent motion and attention. Canadian Journal of Experimental Psychology, 48, 182-204.

\section{NOTES}

1. There were no predetermined configural groups in this experiment; all the items initially appeared in random positions.

2. In a baseline experiment, we found no difference between the conjunction condition and a 300-msec preview condition as display size increased $[F(1,12)=3.70$, n.s.], suggesting that there was a limited search advantage when the preview items were shown only for $300 \mathrm{msec}$ prior to the onset of the new items.

3. Although this was significant here, the difference in errors between the conjunction and the standard preview conditions was not reliable 
both in Experiment 1 and in Olivers et al.'s (1999) experiments. Thus, the speed-accuracy tradeoff found here should not affect the overall pattern of results. In any rate, the crucial comparisons in Experiment 2 (i.e., the conjunction and the LD-CD conditions and the standard preview and the LD-CD conditions) did not show any evidence of speed-accuracy tradeoffs.

4. Two baseline experiments were conducted to compare the effect of displacement size across the LD-CS condition and the LD-CD condition. In the first experiment, 12 participants (all females; mean age, 21.8 years) took part in two conditions: a standard preview condition and an LD-CS condition in which the old items moved vertically one visual degree downward (see Experiment 1 for details). The results replicated those found in Experiment 1, in which the LD-CS condition did not differ in terms of efficiency from the standard preview condition $[F(2,22)=$ $0.6, \mathrm{n} . \mathrm{s}$.]. In the second experiment, 11 participants (all females; mean age, 21.9 years) took part in two separate conditions: a standard preview condition (identical to that of the preceding experiment) and a LD-CD condition. In the LD-CD condition, the old items could move in one of four directions so that their initial configuration was destroyed (e.g., up, down, left, or right) but here they could move only a distance of one visual degree. Nevertheless, the results still resembled those found in Experiment 2: There was a reliable difference between the standard preview and the $\mathrm{LD}-\mathrm{CD}$ conditions $[F(2,20)=3.5, p<.05]$. Here, we still found a decrease in search efficiency when the configuration of the old items changed, as compared with when they stayed the same, even though the average displacement of the old items was controlled for.

5. It is often difficult to make conclusions from absent trials in visual search, since observers may adopt a number of different search strategies before responding absent (e.g., Chun \& Wolfe, 1996).

6. As a control experiment, these conditions were run again, using a target-present or target-absent decision task to show that this change in response from Experiments 1-3 did not affect the results. The data replicated those found here in both present and absent trials (i.e., RTs in the conjunction condition were slower than those in the preview condition $[p<.01]$ and increased more with display size $[p<.01])$, indicating that changing the response in each task did not affect the pattern of results.

7. One point that we would like to make clear is that temporal grouping may indeed play a role in segregating new items from old, allowing new items to be prioritized for selection. In fact, there is nothing to say that temporal grouping and VM cannot work together in unison to bring about optimal search. However, in light of the results found here, the temporal-grouping account as it stands may need to be modified to include other grouping mechanisms, such as spatial configuration, rather than relying solely on grouping over time.

(Manuscript received December 17, 2001; revision accepted for publication February 24, 2003.) 